\title{
Erratum to: The Changing Nature of Happiness
}

\author{
Sandie McHugh
}

\section{Erratum to:}

S. McHugh (ed.), The Changing Nature of Happiness, https://doi.org/10.1007/978-3-319-65651-9

The original version of the book was inadvertently published with the following corrections:

The abstract of Chapter 7 has been incorrectly placed in Chapter 6, which has been now corrected.

Missed out contributors biographies have been included in Frontmatter.

The updated online version of this book can be found at https://doi.org/10.1007/978-3-319-65651-9 and https://doi.org/10.1007/978-3-319-65651-9_6

(C) The Author(s) 2018 